\title{
Fiction and Philosophy in Novel Without a Name and the Disappeared
}

\author{
Roya Jabarouti (corresponding author) \\ Faculty of Modern Languages and Communication, University Putra Malaysia \\ E-mail: roya.jabarouti@gmail.com \\ Gabriel Clement Chua Chen Wei \\ Faculty of Modern Languages and Communication, University Putra Malaysia \\ Manimangai Mani \\ Faculty of Modern Languages and Communication, University Putra Malaysia
}

\author{
Doi:10.7575/aiac.alls.v.4n.2p.1 \\ URL: http://dx.doi.org/10.7575/aiac.alls.v.4n.2p.1
}

Received: 01/04/2013

Accepted: 05/06/2013

\begin{abstract}
While Duong Thu Hung's Novel Without a Name (1995) describes the bloodshed in the jungles of central Vietnam towards the end of Vietnam War (1959-1975), Kim Echlin embarks her narrations in The Disappeared (2009), about a decade after the collapse of Pol Pot's genocide (1975-1979) in Cambodia. Philosophy however, is waved into fiction in order to add layers of depth and meaning to their narrations. Role of ideology and its effect on human life are among the major themes discussed by the authors. This study employs a close study of the above texts to discover the philosophical phrases used by the authors. It also illustrates how philosophy enhances meaning in fiction and contributes to its authenticity.
\end{abstract}

Keywords: Fiction, Philosophy, Vietnam War, Pol Pot Regime, Ideology, Humanity

\section{Introduction}

Duong Thu Hong's Novel Without A Name was published in 1995 in the United States (Huong, 1996). The novel is banned in her home country of Vietnam for rendering the day-to-day realities of the Vietnam War from 1973 to 1975 . It specifically focuses on the conditions of individual Vietnamese soldiers towards the end of this war, in the jungles of central Vietnam. The narrator-protagonist is Quant, a 28-year old officer who has abandoned everything to enlist in the army at the age of 18, full of ideals and promises of communism. However, after years of leading his platoon through all the atrocities during the war he feels disillusioned. On his journey back home, he undergoes an agonizing solitary odyssey that opens a new angle to the promises and realities of war. Not surprisingly, he returns to the community of his comrades, as if only to say: "It's too bad that I have learned the truth, I won't be able to see things in the same way anymore"(Huong, 1996, p.276).

The 2009 novel The Disappeared by Kim Echlin, also published in the U.S., is somewhat like a continuation of Novel without Name. It touches on similar themes albeit set in a different time, place and culture. In this novel, Echlin utilises the unconditional power of love as a leitmotif to express the unforgettable smells and memories of the Khmer Rouge in contemporary Cambodia. Anne the Canadian narrator-protagonist meets the Cambodian Sere in Montreal, where the two fall deeply in love. Nevertheless, Sere decides to leave his Oan Samlanh, Anne (Echlin, 2009, p.43) when the Cambodian borders are opened following the end of Pol Pot's regime in 1979, to find about his family and country. Ten years later, Anne also sets off for the same destination in search of her Borng Samlanh (Echlin, 2009, p.43), her beloved country and Sere(Echlin, 2009, p.203). She walks down the streets and into the ruins, watching and listening to ordinary Cambodians in Phnom Penh. Thirty years later, Anne writes down what she remembers. Anne is in many respects Echlin's mouthpiece to foreground the prolonged trauma suffered by many Cambodians in the aftermath of Pol Pot's brutal regime, even as their country progresses slowly into a peaceful constitutional monarchy. This is profoundly reflected in the words Anne says upon her return: "I had to push again to get rid of the afterbirth, but this word is wrong because it was after death"'(Echlin, 2009, p.150). In both novels, however, the souls of the unnamed disappeared are still wandering and their voices can still be heard, by the authors. The authors write their words, so as to avoid the criminality of silence (Echlin, 2009, p.221).

\section{Weaving Philosophy into Narration}

In the combination of philosophy and literature, there is a literary interpretation of the ideas of philosophers as well as a philosophical treatment of literature. Plato was the one who invented and legitimized the term philosophy and perhaps the first one who practiced his philosophical ideas in the form of dialogues between fictionalized characters. However, 
many writers and philosophers later continued to weave philosophical thoughts and phrases into various forms of genres in literature(Nightingale, 2000, p.14-16).

On the other hand, Patric Suppes believes that a philosophical understanding of meanings in phrases does not occur on the surface level or the second dictionary meaning of the words (Suppes, 2009, p.160). He asserts that since the 'understanding' of this deep level of meaning is based on the inner workings of the human mind, it becomes rather associative (Suppes, 2009, p.160). In other words, this level of meaning becomes highly dependent on the context of a literary work and its author's way of inserting it. Even more so, the interpretation depends on the readers' perceptions. Aristotle goes further by saying that the reader's understanding of the text, notably poetry, carries its last and genuinest meaning (Jabarouti, Shariat, \& Shariat, 2013, p.27). Although Suppess identifies the use of multiple meaningful phrases only to poetry as aforementioned, it can also be found in other genres of literature particularly when the author is trying to convey his thoughts beyond the dictionary meanings of words. Christine Brooke-Rose states the same idea by affirming that the philosophical thought is pushed into an ordinary "narrator/character dichotomy that merely replaces the author/ character dichotomy and harks back to the author as God, present and authoritative and omniscient in his text". She distinguishes philosophical phrases based on how readers try to put unspeakable thoughts and feelings into speakable forms of discourse (Nash, 1994, p.172). She also adds that this notion of hidden thought, which is yet to be perceived and accepted by the reader, is an issue that has been fascinating philosophers and scholars for a long time. Love, life, death, power, humanity, the status of humans in creation, among others are some of the major hidden thoughts in many literary works, a great number of which, if not all, can be found in both the selected texts, namely Novel without Name (Huong, 1996) and The Disappeared (Echlin, 2009).

In these two novels, the writers use philosophical phrases and sentences to convey their ideas about inborn qualities and the aftermath of war, focusing on such experiences as loss, displacement, damage and ruin. In both novels, the writers create contrasts between the subjects of ideologies and those who enforce them as well as between the unlimited thirst of the minority for absolute power and the subjugation of the masses. However, the writers tend to draw such comparisons based on a particular angle from which they look at these themes. In Novel without Name, Huong uses war as the setting and takes the reader along with the narrator-protagonist into the heart of bloodshed and killing to see how the Communist ideology, ignorance, and lust for power can turn the "intact" human being into either targets or instruments of death. She also shows that man is capable of being reduced to a mere animal amidst the urge to subside his most basic needs of sleep, food and sex. Throughout the novel, the reader can feel the warmth of blood gushing forth from the fresh wounds of the soldiers. Their cries, often of pain and agony, in addition to disappointment, if not dissent, can still be heard. Except for a few cases, in Novel without Name (Huong, 1996), dead bodies in varying stages of decomposition are frequently present in the narrative as the reader follows the protagonist into the heart of the jungle. Contrastingly, in The Disappeared (Echlin, 2009), the narrator arrives far later and takes the reader to the streets and museums to feel the strange ghostly absence just by watching the skulls. However, the author foregrounds similar topics of the role and power of ideology in controlling the subjects, and re-enforcing the masters. She also explores human psychology in reaction to both losses and remains. In this novel the reader realises and is explicitly reminded that time is not always a healer.

However, both Huong and Echlin use symbolic descriptions, objects and sounds as well as phrases to reflect their intended themes with astounding clarity. The philosophical phrases involved in both works have added levels of meaning and depth to the simple rendering of historical events as well as the feelings of the characters. All the same, the narrations, settings and characters have contributed to the understanding of the philosophical themes of the authors. This is how the moment of birth, the sweet song of love, the comfort of support and the never ending bouncing of death can be heard in "Bong, bong. Bong, bong. Bong bong..."(Huong, 1996, p.194).

\section{Ideology}

According to Teun A. van Dijk (Van Dijk, 2004), ideology is mainly used in communications and social sciences; however, in everyday use it is referred to as the rigid partisan ideas of others. As he further clarifies, this notoriety falls back on Marx and Engels, who called ideologies "forms of false consciousness'(Van Dijk, 2004, p.728).

Nevertheless, throughout much of the 20th century, especially in Southeast Asian countries, the concept and notion of ideology persisted with notorious connotations and concertpractices. "We have the truth, they have ideologies" (Van Dijk, 2004, p.728); in this way many of the ideologies trigger prolonged and polarised wars as well as struggles between 'Us' and 'Them'. The Communist ideology in both novels is mainly highlighted for its 'dominant' nature. As Teun A. van Dijk (Van Dijk, 2004) also hints, this ideology plays a significant role in "the legitimization of power abuse" (Van Dijk, 2004, p.729) by the minority of the elites who wanted to take the control over the majority and its advantages. The ideology of the Khmer Rouge in Cambodia also began from the Communism of the Vietnamese and later evolved into the "Dark Years" through the espousal of the ethics and ideologies of its leader Pol Pot (Mysliwiec, 2003, p.107). As Teun A. van Dijk (Van Dijk, 2004) asserts in his article, Bourdieu calls ideology the symbolic power and the legitimacy of those who produce discourse, with an emphasis on the subsequent social conditions. Ideology is also manifested in the form of opposition or resistance; in fact it is basically the fundamental interest of a social class that wants to gain power. In addition, ideologies share similar characteristics and are contributed by language as they need to reside in the long term social memory. This kind of knowledge and attribute shared by a ceryain group is generally "presupposed to be the truth" and are turned into mental models of the community (Van Dijk, 2004, p.730). The Khmer Rouge regime and the Communists of Vietnam also invented new terms, such as "forge" (lot dam) meaning "instruments" (Weitz, 2009, p.156), to refer to the people. In The Disappeared (2009), Echlin refers to these mental models and mottos, such as "To keep you is no benefit. To destroy you is no loss" (P.88). As Teun A. van Dijk puts it, "using an ideology is like being able to use a language without being able to formulate the grammar of that language". 
Both Communists and Khmer Rouge members, as presented in the novels, rarely have full control over and understanding of their discourses and practices. In a nutshell, ideology provides the subject with a self-image and attempt to turn them into self-controlled images. After being indoctrinated, neither the Vietnamese Communists nor the Khmer Rouge soldiers can cease to become communists or socialists overnight; ideologies continue to shed their shadow over their entire lives. However, from the beginning the authors use philosophical phrases to indicate this fact. Beginning with the title, Novel Without a Name (Huong, 1996) suggests the types of ideas, phenomena and events that it involves: Things that are too bad, too disastrous to be named; a narration that is too all-encompassing that cannot be given a single title; an abstract ideal that triggers a concrete prolonged fatality, the annihilation of humanity and the subversion of the purpose of creation. Novel Without a Name (Huong, 1996) is also paradoxically a novel that gives particular attention to the selection of the names it includes, such as "the Gorge of Lost Souls"(Huong, 1996, p.2), "the Valley of the Seven Innocents", the battle of "Waves of the Red River" (Huong, 1996, p.207). Duong Thu Huong begins the novel where an anonymous character hears the mournful sobs and howls of the wind in the darkness of the night and ends when the same character hears the familiar mournful chant, and watches the spreading colour of blood.

On the other hand, The Disappeared (Echlin, 2009) directly refers to the aftermaths of a genocidal regime in the past, during which numerous people disappeared. Although Kim Echlin (Echlin, 2009) does not specifically state it, she is so much concerned that they should be remembered by future generations fortunate enough to be spared first-hand experiences of such atrocitites. The author gives a name and identity to the nameless masses of victims and investigates the intangible yet significant entities that have disappeared even among the survivors, such as their sense of individuality, courage and humanity. As the title implies, the novel looks at a fatal phenomenon from outside, and as we later find out, from the point of view of an outsider. Contrastingly, the narration beings with a name, which is neither significant nor symbolic. It begins with the name of an ordinary driver from the crowd of drivers in the Russian market in Cambodia, and continues to fill the novel novel with the names of many ordinary Cambodians. Moreover, man odd sobriquets are symbolically capitalised for further emphasis, such as "Can't Quit", "Blues"(Echlin, 2009, p.3) and "No Lie"(Echlin, 2009, p.4). In the story, the protagonist presents death and loss by persistently pointing to parts of the human body throughout the narrative: "the light in Mau's eyes", the"bones" (Echlin, 2009, p.3) of the dead after thirty years, and "your voice" that still can be heard. To put it in Anne's words, "our disappeared where every everywhere, irresistible, in waking in sleeping"(Echlin, 2009, p.120).

\subsection{Birth of Ideology}

The unnamed short fat character on the train, who nevertheless holds a very high position in the Vietnamese government, discloses the truth behind the birth of any ideology and ideal. As he puts it, "civilization is a long difficult journey, and we don't have much time. Life is short. We've got to find another way... that's exactly what being in power is all about"(Huong, 1996, p.160). As one of its major characteristics, a civilized society supplies all citizens with equality, however, for an even better life one must be smart enough to find a shorter and faster way to gain power over the others. As the fat man continues, "the ultimate pleasure: the gratification of power. Money. Love (Huong, 1996, p.162), presupposes the position of authority. Later he explicitly states that lies and tricks are the shortcuts to power and ultimate gratification: "guaranteeing a small number of people a civilized existence, why, there is nothing easier" (Huong, 1996, p.162). Finally the author makes him confess the authorities' manipulation of the public using the power of language: "the word comrade can mean anything. From a linguistic point of view, it is a lie. From a historical point of view it's an adaptation, and from a practical angle, well, it's just a leader's trick" (Huong, 1996, p.159). Put it differently, by creating ideals for ordinary people, the smarter minority use their strength and talent to obtain an absolute power over them. "That's the art of governing. Spreading the word...the less it is true, the more we need to believe in it" (Huong, 1996, p.161). Patriarchal songs, revolutionary thoughts, school text books and intellectuals who get paid for it are the various ways of spreading the word.

In The disappeared (2009), the author looks at the same issue but from the perspective of subject majorities, namely the Cambodian people. As Anne describes, "people showed peculiar courage, by gathering, by listening, seduced by the possibility of a different life"(Echlin, 2009, p.156). She explains how the minorities are trying to sensationalise the public, and how intellectuals have been employed to rationalize their ideas. This statement also explains the way ideologies are spread in the societies. In the post-Pol Pot period, the Opposition group start promising better ways of life, while in reality they are preparing the ground to build up their own institutions of power.

3.2 Targets of ideology

"That ideal, well, the kids need it. And it's all we need to turn them into monks, soldiers, or cops. And it worked, whether it was the revolutionary uniform or nationalist police cap" (Huong, 1996, p.160). Needless to imply, the author puts the exact words into the mouth of the government official, to tell the readers about the main targets of the ideology. With their minds still fresh and eager, the youth's perceptions are fertile for indoctorination, while adults have already been tainted or enlightened. Older people, therefore, are likely to be more problematic and rebellious, whereas younger ones are naturally full of hopes and dreams of a promising future. This future, as the author implies, is alluringly sketched in such words as "comrade" or disguised in "the revolutionary uniform".

In The Disappeared (2009), Echlin puts the words directly into the mouth of the targets of ideologies, namely the "kids". Anne learns from Sokha, Serey's younger brother, that children were separated from their parents to live and to be trained in children units, where they would be called "Young Comrades"(Echlin, 2009, p.125). Those children were forced to confess every night, about anything that could hinder Khmer Rouge's revolution. Sokha describes how his false report caused the death of a weak boy in the children's camp. To make matters worse, after describing the scene in which the boy's body parts were thrown into the paddy fields as fertilizer, Sokha leans back, closes his eyes and whispers a song: "We children love Angka limitlessly, The light of revolution, equality and freedom shines gloriously, 
Oh Angka we deeply love you, We resolve to follow your red way". There is no better way, for an author, to insert her message into the narrative. Sokha had been transferred into a self-controlled instrument of the Angka organization, a "young comrade" who could coldly walk in the bloody "red" way of Angka (Echlin, 2009, p.125).

\subsection{Death of ideology}

"Words are like everything else in life, they are born, they live, they age and they die"(Huong, 1996, p.161). Duong has already explained how ideologies are born and spread around by intellectuals and cultural carriers. Now, she describes the way idealised and idolised words perish or die away. As she implies, by the passage of time and witnessing the consequences, people discover the untrue and dishonest nature of the promises of ideologies. This may be another reason why the author has not chosen a name for her novel; a novel without a name is not one that once came in vogue and may later fall out of trend. A novel without a name is something to be there forever. But in this novel, she refers to many "Comrades' Chants" that once motivated young Vietnamese soldiers, and describes them as "words that flowered, bore fruit" in the early years of the Vietnam War. Yet in the final years, Quant, the narrator-protagonist sheds light onto their real nature: "Arrows. Crosses. Tinley lines and dots. A map so detailed, so meticulously drawn. So useless" (Huong, 1996, p.167). So useless are all the promises and words of Socialism or Communism that have generated the Vietnam War. Even worse, it is "impossible to make out anything" (Huong, 1996, p.167) of them. They are only a bunch of empty words that have begun to fade, to "wither" (Duong 161), to "rot faster than [any false] love" (Huong, 1996, p.160) and turn into "mouldy old memories" (Huong, 1996, p.160). To put it another way, he asserts that "Amnesia doesn't have ideology" (Huong, 1996, p.160). Ideologies are too shallow, too wordy and too false to be worth residing deep within the spirit of man, though on the other hand, they are too dishonest and too agonising to the point that they leave nothing for humankind, except mental suffering and loss.

Echlin (2009) also explicitly states that the truth will finally show itself up and put an end to the lies of ideology. "Three things cannot be hidden, the sun, the moon and the truth" (Echlin, 2009, p.189). Nevertheless, she is more pessimistic, or realistic in her proclamation; she believes truth will finally show up but only when it is too late. According to Huong, Truth turns up after it has brought about loss, when "bones work their way to the surface" (Huong, 1996, p.3). As Will puts it, "the truth will set you free, but it will first piss you off" (Huong, 1996, p.74).

\section{Leftovers of the ideology}

Nameless humanistic disasters of the Vietnam War, the disappeared people of the Cambodian Genocide and their still unresolved aftermaths could at one time be rationalised by means of the ideologies that have triggered them. Regardless of how they were implied, they have claimed victims at various levels. On the one hand, they have committed atrocities against non-military people and civilians by literally taking their lives, and on the other, they have brought irretrievable omissions and absences into the lives of the survivors, leaving them to mourn the loss of their loved ones as well as the loss of humanity and humanness on the whole. Both Duong (Huong, 1996) and Echlin (Echlin, 2009) attempt to disclose the depths and layers of these losses by means of the philosophical words and manners of their characters.

\subsection{Loss of humanity}

"This war was a paradise for them. They lived well, always satisfied. We offered them unlimited blood. This was a meager tax compared to the tribute the bombs claimed from us" (Huong, 1996, p.69). When reading the first sentence of the above statement, every familiar reader is reminded of the promises of the Communist Party to the Vietnamese. Undeniably, the promise in question refers to that of Vietnam becoming a paradise for its citizens by the end of the war. Yet the above statement ends up to be an irony. As the reader progresses, it is revealed that Quant the narrator is referring to the nest of fleas he spots in the bunker's roof beams. Unlimited number of casualties in the war has offered fleas enough blood to feed on and subsequently prosper. Nevertheless, as he asserts, this amount of blood is nothing compared to the damages wrought by firearms and explosives used in the battlefields. In fact, Duong is implying through the fleas that the promises of Communism is better at serving non-humans instead of human beings. She uses the same sense of irony by calling a battle triumphal when it had been so fatal: "This battle was a triumph. It was called "Waves of the Red River"” (Huong, 1996, p.207). Also, by saying that "bullets may miss people, but no one dodges a bullet" (Huong, 1996, p.207), Duong implies the same idea. In addition, she indicates that human faith in times of war is no longer a matter of choice, but in fact a matter of chance. In the midst of violence, people have no way running away from death. In other words, death is the only product of war.

In The Disappeared (Echlin, 2009), Anne indicates the same agonizing fact by simply describing the emotional status of people: "It was ordinary that people were missing in this place. As ordinary as missing an arm or a leg"(Echlin, 2009, p.62). Hence, the question that immediately comes into the mind of the reader is, "what number of losses might result in such indifference to death among the Cambodians?" As Sere continues, "there was no one to witness us and so we were witnessed by the nameless missing and by the generations to come" (Echlin, 2009, p.94). This account reveals the high number of deaths and killings during the merciless regime of Pol Pot. This loss is so severe to the extent that there is nobody left to witness the brutality and crimes of the government; in fact, people only hope that they will be remembered well into the future.

\subsection{Loss of humanness}

In Novel Without a Name (1995), we read about Quant's father that "the only way he did not starve, was by imitating his neighbours" (Huong, 1996, p.117). His father's lifestyle has changed after returning from the Anti-French Resistance. Thereafter, he is not capable of making a living inasmuch the same way as the other villagers. To make matters worse, he is not even able to sympathise with or understand his family members. Quant says "my father had neither the strength nor the motivation to do much" (Huong, 1996, p.117). Quan's father is the perfect embodiment of the people who have been indoctrinated by the authorities and have turned into their self-monitored instruments. War 
not only takes life away from its victims, but also takes the ability to live a normal life away from the survivors. Later, Quant will at a later part of the novel explain this effect with crystal-clear precision:

"Never. We never forget any ting, never lose anything, never exchange anything, never undo what has been done. There is no way back to the source, to the place where the pure, clear water gushed forth. The river had cut across the countryside, the towns, dragging refuse and mud in its wake (Huong, 1996, p.148).

From the very beginning in The Disappeared (2009), Anne's fathers proclaims that "force turns the one subjected to it into a thing"(Echlin, 2009, p.32). In the pages that follow, when Anne is wandering in the streets of Cambodia, she finds the embodiments of this statement. While after the subversion of Pol Pot regime, ordinary people begin to regain their long lost passion in the use of language, there are still those who remain static and incapable of doing so. They are the previous tortured ones, the true instruments of Angka: "For them, there was no exhilaration in language. Virtue is terror, terror is virtue. Without slogans, they found themselves speechless" (Echlin, 2009, p.116). Even after the attacks by Vietnam, when Pol Pot's soldiers flee to the countryside, Echlin describes the Jungle camps to be filled with "young men who knew no way of life but war, restless and waiting" (Echlin, 2009, p.130). Their spirits have been drastically transformed by the slogans and doctrines of the Angka regime that they had turned into "things". Anne also observes Sokha with "iron in his soul" because "their words were buried into him". Years after the fall of Pol Pot, although at times "he was tempted by ...clean air...Clean skin...But inside his nostrils the air stank of corpses and burning hair and diarrhea" (Echlin, 2009, p.116), Sokha himself is aware of this fact, when he says, though still alive, he is a first-hand victim of the previous regime. Also, in Choeung Ek, when Anne goes to visit the cases of skulls, a man who had at the time of Pol Pot's regime witnessed and participated in some of the killings explains: Now "I am a living dead. I have my body, I can move, I can speak, I can eat, but I am nothing (Echlin, 2009, p.88). At last, by rendering all the above, Echlin declares that "this thing is sure: Time is no healer"(Echlin, 2009, p.12).

\subsection{Loss of humanity}

Amongst the very first images in Novel Without a Name (1995) is that of Quant's description of the decay of the human body:

"So this was how graceful, the girlish bodies rotted, decomposing into swollen old corpses...Maggots swarm in their wounds, their eyes and mouth. Fact white leaves ... plunging in and out of them in a drunken orgy" (Huong, 1996, p.3).

However, this bodily decay can be extended to understand the corruption of humanity in times of war. As a result of war, human bodies have turned into nesting grounds for the lowliest and most disgusting animals. In his description he explains how maggots are feeding from the most precious portions of the bodies: veins, eyes and mouths, which is an irony to the promises of Communism. The promise of a paradise for mankind, respect and glory for the Vietnamese, has instead turned this land into a haven for fleas and maggots.

Even worse is when the human beings take pleasure in the taste of human flesh and blood. Quant remembers his soldiers inviting him to taste their cookies: "Chief, if only you knew! Orangutans are almost humans. There is no tastier flesh" (Huong, 1996, p.9). This decline in humanity is also evident when some of the soldiers resort to bestiality and have sex with animals. Animalisation of human beings, is in fact an irresistible outcome of war. Moreover, because soldiers were living in as community, every member is expected to conform to the tendency of the group to at least "demonstrate its power" (Huong, 1996, p.9). Even Quant cannot resist this claim of membership and is obliged to taste their food. "It was done. I had eaten it....the taste of human flesh in my mouth" (Huong, 1996, p.11). In another situation it is implied that war makes 'killing' the profession of the human. When Quant asks of Bien: "It's a coffin, isn't it?", he replies “-yes, our special product” (Huong, 1996, p.180). This is again highlighted when Bien explains: "...the only way to get the coffins over the mountain is on the back of those men" (Huong, 1996, p.192). In the end, Quant himself confesses that "like other soldiers, I was prepared to accept this strange gift. Fighting and dying; two acts, the same indescribable beauty of war" (Huong, 1996, p.192).

In The Disappeared (209), Echlin similarly emphasizes on the loss of humanity as the most obvious outcome of war. It is evident when Sokha remembers the time when one of the Angka soldiers offered him some liver and said: "One man's liver is another man's food"(Echlin, 2009, p.128), in order to test his loyalty to the regime. Even after the collapse of Angka's regim, Will describes the situation in Kampong Cham as such: "Everything eats everything else" and then explains that all these food in Cambodia is fertilized with human flesh and then sadly continues: "But we gotta eat" (Echlin, 2009, p.107). The theme of the loss of humanity as the result of war is explicitly asserted in the novel, when Will says: "People have top brain and bottom brain. The bottom brain is for survival and seduction...the guys were turned to bottom brain life" (Echlin, 2009, p.96). In order to foreground this theme, Echlin (2009) presents a situation in which a young girl has been arrested by the soldiers of the previous regime. "She does not even wear a number. She was not even worth a number. This is war. This is darkness" (Echlin, 2009, p.110). This explanation reflects Echlin's protest against the position of human beings during the Pol Pot Genocide. The individuality of human beings was ignored and they were reduced to numbers. The girl in the description, was not worth even to that level. She was readily available to any torture or killing in the Tuol Sleng. Echlin uses a famous slogan used by those soldiers to show the dark heart of Angka regime, which says: "Better to kill an innocent than to leave one traitor alive. This is the heart of Purity". Later, she elaborates that "corruption likes darkness" (Echlin, 2009, p.109).

\section{Traumatic effects}

In one of the most general definitions of trauma, as proposed by Cathy Caruth (Caruth, 1995), a leading theorist in trauma studies, trama has been defned as a response to "an overhelming experience" of a shocking or "catastrophic event". This response, as Cruth (Caruth, 1995) asserts, usually occurs in a "delayed" and "uncontrolled" way, and in 
the form of repititive nightmars or "appearance of hallucinations" (Caruth, 1995, p.11). In Huong's Novel without Name (1995), the author tries to symbolically depict the traumatic effects of the Vietnam War on the lives of the Vietnamese soldiers when she says ,"you'd need a miracle to get rid of the smell of the blood" (Huong, 1996, p.42). Through this sentence, Huong (1995) hows that war makes the connotations of death persist in the human psyche and mentality. The scarlet sands, the blood-strained horizon, blood-spattered clouds and everything else that Quant the protagonist sees seems to have the color of blood. In other words, the author implies that war is capable of sadistically reshaping the perceptions of the most ordinary things and events in human life to the extent that it is almost impossible to escape from it.

All the same in The Disappeared (2009), the author repeatedly refers to the persistence of the smell of death and says, "...the rotting stench of death stained the insides of his nostrils" (Echlin, 2009, p.19). Even years after the collapse of Pol Pot regime, Sokha, Serey's brother is startled at smells. This not only affects Sokha; all over Cambodia, people get startled at bad smells, of cigarette, of rotting garbage, etc. which they call "rumsew". Kim Echlin (2009) uses the olfactory sense to show the traumatic effects of the merciless regime. Psychologically this reaction is called "Olfactory panic attacks" (Dropkick 73). It occurs when every bad smell reminds individuals of the sulphourous smoke of the bombs and the bullets, although they may not exactly remember the event (Dropkick 98 ).

As a result of the massive scale of casualties and fatalities, the implication of many words also change for the people involved. Life, hope and happiness turn into meaningless phenomena. In Novel Without a Name (1995), the protagonist mourns over his own life: "Here I am, 28 years old, temples graying...I thought of my youth, how it had been ticked by in long, merciless years of pain. Why this fate, why it had been reserved for me?" (Huong 72). Elsewhere he says: "What a bitch, this life, the survivor has closed his eyes, waiting for a bullet, while the death man stared wide-eye into space"( Duong, 22). Saying so, the author is trying to show that concepts of life and death have lost their connotations. She is, in fact, ironically referring to the collective situation the entire Vietnamese people; while the souls of the dead ones are seeing the truth, the survivors have ignorantly closed their eyes to reality. In The Disappeared (2009) Anne implies the same issue by saying that "they say that the souls of the dead wander if the monks don't pray over the bodies. But I think the souls of the living wander when their dead are lost" (Echlin 144). This is the situation that Kim Echlin (2009) claims happened to the survivors of the Cambidian Genocide; they remain haunted by a never-ending trauma until years later. Ironically, she asserts that those who were killed are the secondary victims. The real primary victims are the survivors. As Echlin puts it over the dead of Sere: "I cannot be alive if you are dead" (Echlin 163).

\section{Conclusion}

In Novel Without a Name (1995), the protagonist speaks from the heart of wounds, bleedings, grief and pain. He realizes and describes the disillusionment of the soldiers. Nevertheless, he tells the reader that bloodshed is fostered from every corner of Nature. The horizon, the sky, the hills, the waves, here and there the wind blows echoing death, but no one speaks of it to the others. The author is, in fact, attempting to warn us of the surreality of the glinting scarlet and the emptiness of the promises. The Disappeared (2009) looks at the skeletal remains of the dead, and watches the fear of the survivors from their swollen skins and silenced mouths. It discusses the issues surrounding war and bloodshed. The author points out to the losses in the people's life and implies that despair keeps haunting the survivors while hope condemns them to survive.

Finally, both authors are of the idea that "someone must act in the name of the lost" (p.205 Echlin); the innocent individuals who lost their lives, or those who survived only to suffer from the loss of their loved ones. The authors are worried about the loss of humanity in the war of ideologes and the lust for power, and believe that silence is s crime. Undeniably, it is indeed true that the atrocities of war, spearheaded by bloodthirsty leaders with conflicting ideologies pitted against the masses, have led to deeply-etched "scars" that have simultaneously become part and parcel of a nation's history, culture and identity, which is very much the case of presently-developing countries such as Cambodia and Vietnam. However, this is just the bigger picture. Although fictional at best, literary works such as Duong Thu Huong's Novel Without a Name (1995) and Kim Echlin's The Disappeared (2009) are of great significance because they provide readers with an invaluable insight into the countless stories of individual desperation, suffering, grief, loss and hopelessness. It is hoped that this study on the effects of trauma among survivors of genocidal regimes and conflicts depicted in the selected texts will create greater awareness among readers of the devastating consequences of manmade violence on individual lives.

\section{References}

Caruth, C. (1995). Trauma: Explorations in memory. JHU Press.

Echlin, K. (2009). The disappeared (pp. 1-235).

Huong, D. T. (1996). Novel without a name (pp. 1-289).

Jabarouti, R., Shariat, A., \& Shariat, A. (2013). Effect of Persian classic poetry on the level of stress hormone in retired academicians. Journal of Poetry Therapy, 27(1), 1-9.

Mysliwiec, E. (2003). The case of Cambodia. Dialogue in pursuit of development, 2, 107.

Nash, C. (1994). Narrative in culture: The uses of storytelling in the sciences, philosophy and literature. Routledge.

Nightingale, A. W. (2000). Genres in dialogue: Plato and the construct of philosophy. Cambridge University Press.

Suppes, P. (2009). Rhythm and Meaning in Poetry. Midwest Studies in Philosophy, 33, 159-166.

Van Dijk, T. A. (2004). Politics, ideology and discourse. Encyclopedia of language and linguistics, 1-32.

Weitz, E. D. (2009). A century of genocide: Utopias of race and nation. Princeton University Press. 